\title{
Investigating relative contributions to psychiatric disease architecture from sequence elements originating across multiple evolutionary time-scales
}

\author{
Authors: Mashaal Sohail ${ }^{1,2 *}$
}

\author{
Affiliations: \\ ${ }^{1}$ Centro de Ciencias Genómicas, Universidad Nacional Autónoma de México; Cuernavaca, \\ México. \\ ${ }^{2}$ Department of Human Genetics, University of Chicago; Chicago, USA. \\ *Corresponding author. Email: mashaal@ccg.unam.mx
}

\begin{abstract}
It remains an open question when and why psychiatric and other disease evolved in human evolutionary history. We harness large genome-wide association studies and recent studies that have identified human-gained epigenetic marks, selective sweeps, archaic introgression, and accelerated evolution to help tackle this question by assessing the enrichment of heritability in these sequence elements for 41 complex traits. We find that human-gained epigenetic elements in the fetal brain harbor variants affecting skeletal, dermatological, and respiratory traits early and psychiatric traits later in development, that genomic sequences under selection since our divergence with Neanderthals are enriched in heritability for autism, and that regions depleted in ancestry from other hominids contribute more to heritability for psychiatric than other traits. Psychiatric disease may be a concomitant outcome of the evolutionary processes that made us uniquely human.
\end{abstract}

One-Sentence Summary: Variants that cause autism and other psychiatric disease today colocate with sequence elements that have been important during human evolution. 


\section{Main Text:}

Recent commentaries on common disorders have rallied for a shift in vocabulary, calling to speak of "dimensions" rather than "disorders," of genetic "variability" rather than genetic "risk," and to ask what are the relevant quantitative traits for any "disorder?" (1-6) Such calls from within genetics, psychology and disability studies are seeking to understand conditions such as autism in a non-pejorative manner and suggesting an evolution-informed framework. This shift in vocabulary implies different diagnostic and public health procedures as well, especially ones focusing on dimensional approaches and prevention. We consider the specific case of psychiatric traits relative to other complex traits and disease. The nature and etiology of mental illness is often ambiguous (7). As defined in the Diagnostic and Statistical Manual of Mental Disorders (DSM), there were 106 psychiatric disorders in 1952 (DSM-I) and 297 in 1994 (DSM-IV). In recent history, their conceptualization went in the $20^{\text {th }}$ century from a reaction model ascribing them as a maladaptive response to socio-environmental sources of distress to a Neo-Kraepelinian model seeing them as fixed disease entities (7). Moreover, the role of such psychiatric traits in our deeper evolutionary history is not well understood. In this study, we approach this fundamental question by estimating the relative contribution of sequence elements originating across multiple evolutionary timescales to psychiatric, respiratory, skeletal, metabolic, cardiovascular, immunological, and other trait domains.

Our estimations rely on using genetic variants associated with 41 independent complex traits $(8)$, genomic annotations marking sequences that have evolved at different periods of human evolutionary history (9-14), and the statistical framework of stratified linkage disequilibrium score (S-LDSC) regression (15). S-LDSC estimates whether a genomic region is enriched or depleted in heritability for a trait or set of traits, capturing the contribution of variants in that genomic region towards trait variation, and whether this contribution is more or less than expected given the relative proportion of variants in that region. Previous meta-analyses across traits using S-LDSC have found a heritability enrichment in epigenetic elements (15), younger alleles, and higher nucleotide diversity regions, among others (16). Most recently, Hujoel et al showed an enrichment of heritability in ancient enhancers and ancient promoters, as well as in promoters of constrained genes (8). They also presented a signal of enrichment across traits for human-specific promoters. Further, another recent study showed that variants introgressed from Neanderthals and shared across multiple Neanderthal populations are enriched in heritability for some traits (17). 


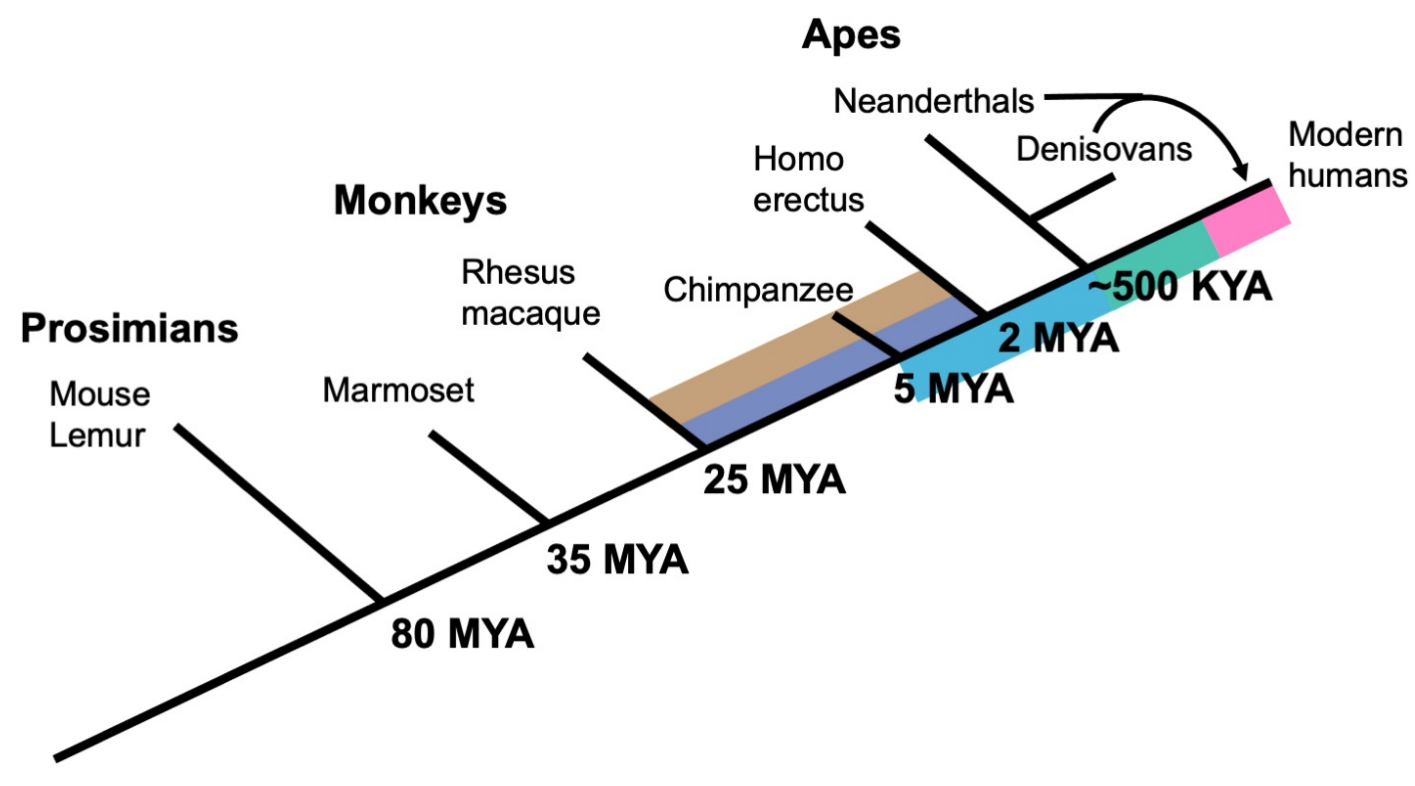

Figure 1. Evolutionary tree depicting the time windows of the origins of genetic and epigenetic sequences analyzed in this study. We analyze fetal human-gained enhancers and promoters (11)(purple), adult human-gained enhancers and promoters (12) (brown), human accelerated regions (9)(blue), ancient selective sweeps (Extended Lineage Sorting ELS;(14))(green), putatively introgressed variants from Neanderthals (Sprime;(13)) (pink) and genomic regions depleted in Neanderthal and Denisovan ancestry (10) (pink). Purple + brown intervals mark epigenetic gains in the cerebral cortex while the other color intervals mark genetic gains. Cladogram showing evolutionary divergence adapted with permission from Miller et al (2016)(18).

However, to our knowledge, this study is the first to analyze the role of a range of human-gained genetic and epigenetic sequence elements originating at different times in shaping complex traits and disease evolution (Fig. 1). We study the following genomic annotations marking different evolutionary periods: (A) Epigenetic elements that gained novel function in the fetal brain since our divergence with rhesus macaque (H3K27as and H3K4me2 histone modification peaks in the fetal cerebral cortex gained in humans compared to mouse and rhesus macaque) at different developmental stages or post-conception weeks (p.c.w.) (Fetal humangained (HG) enhancers and promoters at 7 p.c.w, 8.5 p.c.w., and 12 p.c.w.) (11), (B) Epigenetic elements that gained novel function in the adult brain since our divergence with rhesus macaque (Adult human-gained (HG) enhancers and promoters) (12), (C) Fastest evolving non-coding regions of the human genome (Human accelerated regions or HARs) (9) (D) Ancient selective sweeps from the extended lineage sorting method capturing human-specific sweeps relative to Neandertal/Denisovan (14), (E) Regions depleted in Neanderthal ancestry (10), (6) Regions depleted in Neanderthal and Denisovan ancestry (10), and (F) Putatively introgressed variants from Neanderthals (13). These annotations constitute different numbers of regions, genomic sizes and proportion of total common variation (Table S1). 
We meta-analyzed across 41 independent traits previously analyzed in Hujoel et al (2019) (8) from the UK Biobank and other GWAS. In our analyses, we compare and contrast trait domains, using grouping of traits as primarily environmental, psychiatric, immunological, dermatological, skeletal, reproductive, metabolic, cardiovascular, gastrointestinal, or endocrine as defined in the GWAS Atlas (19). These GWAS have an average sample size of 320,000 $(\mathrm{N}=10,263-459,324)$ (Fig. S1) and the traits analyzed in the GWAS range in heritability from $0.92 \%$ to $67 \%$ (Fig. S2). Specifically, we also considered all psychiatric traits as a group compared to all non-psychiatric traits.

Using S-LDSC, for these 41 traits, we analyzed our test annotations in a model simultaneously incorporating several other regulatory elements, measures of selective constraint, and linkage statistics (baselineLDv2.2 with 97 annotations $(8,15,16,20)$ (Figs. S3 - S4)) to estimate heritability enrichment $\left(h^{2}(C)\right)$ while minimizing bias due to model misspecification. Further, in the relevant human-gained brain epigenetic mark analyses, we added all epigenetic fetal and adult brain regulatory elements from the Epigenome Roadmap Project 25 state model (21) to our models, and also considered conditional analyses using the baseline model as recommended in (22) to estimate the unique contribution $\left(\tau_{k}^{*}\right)$ of these human-gained brain epigenetic marks.

Meta-analyzing across 41 independent traits from UK Biobank and other GWAS, we find a significant heritability enrichment for fetal human-gained enhancers and promoters expressed in the cerebral cortex at 7 p.c.w. $\left(h^{2}(C)=2.71, \mathrm{p}=1.95 \times 10^{-5}\right)$, at 8.5 p.c.w. $\left(h^{2}(C)=3.01, \mathrm{p}=\right.$ $\left.8.40 \times 10^{-5}\right)$, and those expressed in the occipital cerebral cortex (visual processing center) at 12 p.c.w. $\left(h^{2}(C)=2.26, \mathrm{p}=1.79 \times 10^{-2}\right)$ at FDR $<0.05$. (Fig. 2). We also observe a significant heritability depletion in genomic regions depleted in Neanderthal ancestry $\left(h^{2}(C)=0.83, \mathrm{p}=\right.$ $\left.2.02 \times 10^{-5}\right)$, and in regions depleted in Neanderthal and Denisovan ancestry $\left(h^{2}(C)=0.80, \mathrm{p}=\right.$ $\left.1.144 \times 10^{-5}\right)$.
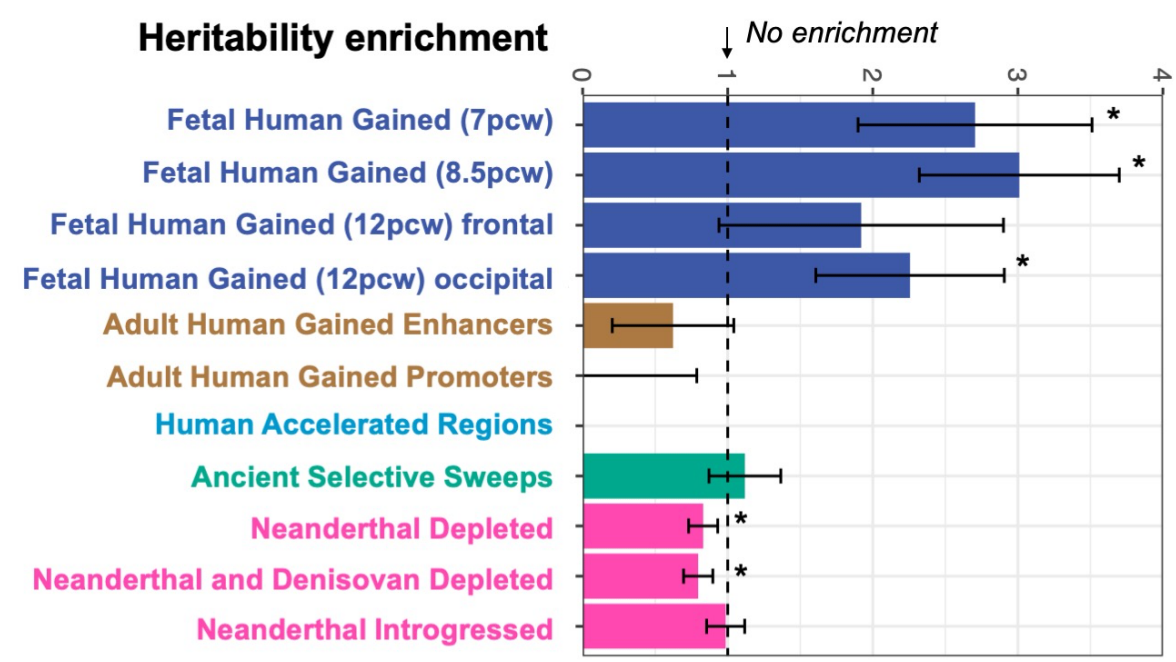

\begin{tabular}{|l|l|l|}
\hline $\begin{array}{l}\text { Proportion } \\
\text { of SNPs }\end{array}$ & $\begin{array}{l}\text { \# Traits } \\
\text { Enriched }\end{array}$ & $\begin{array}{l}\text { \# Traits } \\
\text { Depleted }\end{array}$ \\
\hline 0.0085 & 6 & 1 \\
\hline 0.0044 & 2 & 1 \\
\hline 0.0031 & 0 & 1 \\
\hline 0.0044 & 0 & 0 \\
\hline 0.0048 & 0 & 0 \\
\hline 0.0008 & 0 & 0 \\
\hline 0.0003 & 0 & 1 \\
\hline 0.0040 & 1 & 0 \\
\hline 0.0272 & 0 & 8 \\
\hline 0.0154 & 1 & 8 \\
\hline 0.0074 & 0 & 0 \\
\hline
\end{tabular}

Figure 2. Heritability enrichment analysis in a meta-analysis across 41 traits. Asterisks show significance at FDR $<0.05$. This analysis was jointly performed with all genomic annotations in the baseline LDv2. 2 model $(8,15,16,20)$. The fetal human-gained enhancers and promoters were further jointly analyzed with all fetal brain regulatory elements, and the adult human-gained enhancers and promoters with all adult cerebral cortex regulatory elements from the Epigenome Roadmap project (21). Adult human-gained promoters and human accelerated regions are the smallest annotations, and S-LDSC 
estimates out-of-bounds heritability values (see supplementary text) that are not significant for these. Error bars show confidence intervals.

For each epigenetic or genetic element analyzed, we next investigated their heritability enrichments in traits from different domains (Figs. S5 - S15). First, considering the period from our divergence from the most recent common ancestor with rhesus macaque $(\sim 5$ million years 135 ago), for fetal $\mathrm{HG}$ regulatory elements at 7 p.c.w., the enrichment derives from traits across several domains at FDR $<0.05$ (ulcerative colitis, heel T score, balding type I, FEV1-FVC ratio, height, waist-hip ratio, forced vital capacity, and systolic blood pressure) (Fig. 3, Fig. S5). We verified that this signal is likely due to activity in the brain of the human-gained epigenetic elements (Fig. S16) for several of these traits, even though a proportion of the fetal humangained brain elements also overlap with regulatory elements in other tissues (Table S2). Psychiatric traits as a group become enriched at 8.5 p.c.w. $\left(h^{2}(C)=3.19, \mathrm{p}=5.74 \times 10^{-4}\right)$ and at 12p.c.w in the frontal cortex $\left(h^{2}(C)=4.20, \mathrm{p}=2.09 \times 10^{-4}\right)$ (Fig. 4A). Interestingly, at 7 p.c.w, non-psychiatric traits are significantly more enriched for heritability than psychiatric traits (Fig. $4 \mathrm{~B}$, Wilcoxon $\mathrm{p}=0.005$ ). At 12 p.c.w., in the frontal part of the cerebral cortex, known to be involved in attention, planning, and executive control (23), psychiatric traits are more significantly enriched for heritability compared to non-psychiatric traits (Wilcoxon $\mathrm{p}=5.31 \times 10^{-}$ ${ }^{4}$, Fig. 4B). We also verified that this signal indicates a unique contribution of the brain humangained epigenetic elements using a conditional analysis (Wilcoxon $\mathrm{p}=9.17 \times 10^{-5}$, Fig. S17). Depressive symptoms, anorexia and neuroticism present the highest point estimates for heritability enrichment in the frontal cortex HG elements at 12 p.c.w. (Fig. 4C, Fig. S7).

Next, considering the period since human divergence from the most recent ancestor with chimpanzee ( $\sim 5$ Million years ago), and the period since human divergence with Neanderthals/Denisovans ( $>300,000$ years ago), we consider the human accelerated regions and ancient selective sweeps post Neanderthal/Denisovan respectively (Fig. 3, Fig. 5A, Figs. S11S12, Fig. S18). We observe a significant enrichment of heritability for autism in the humanspecific sweeps $\left(h^{2}(C)=1.66, \mathrm{p}=1.72 \times 10^{-3}\right)$ and a non-significant depletion in the HARs $\left(h^{2}(C)=-6.82, \mathrm{p}=0.81\right)$. We also observe the same pattern for schizophrenia $\left(h^{2}(C)=2.17, \mathrm{p}=\right.$ 0.05 human-specific sweeps; $h^{2}(C)=-14.07, \mathrm{p}=0.09$ HARs), suggesting that variants that lead to autism and schizophrenia today were under positive selection in human evolutionary history since the time of divergence with Neanderthals but not necessarily earlier in the period of divergence from chimpanzee. However, the HARs make a very small proportion of common SNPs making their S-LDSC analysis under-powered (Table S1). Psychiatric traits as a group show a pattern of higher enrichment compared to non-psychiatric traits in the human-specific selective sweeps though this effect is not significant (Wilcoxon $p=0.21$ )(Fig. 5A). 
bioRxiv preprint doi: https://doi.org/10 1101/2022 02 28.482389; this version posted March 1, 2022. The copyright holder for this preprint (which was not certified by peer review) is the author/funder, who has granted bioRxiv a license to display the preprint in perpetuity. It is made available under aCC-BY-NC-ND 4.0 International license.

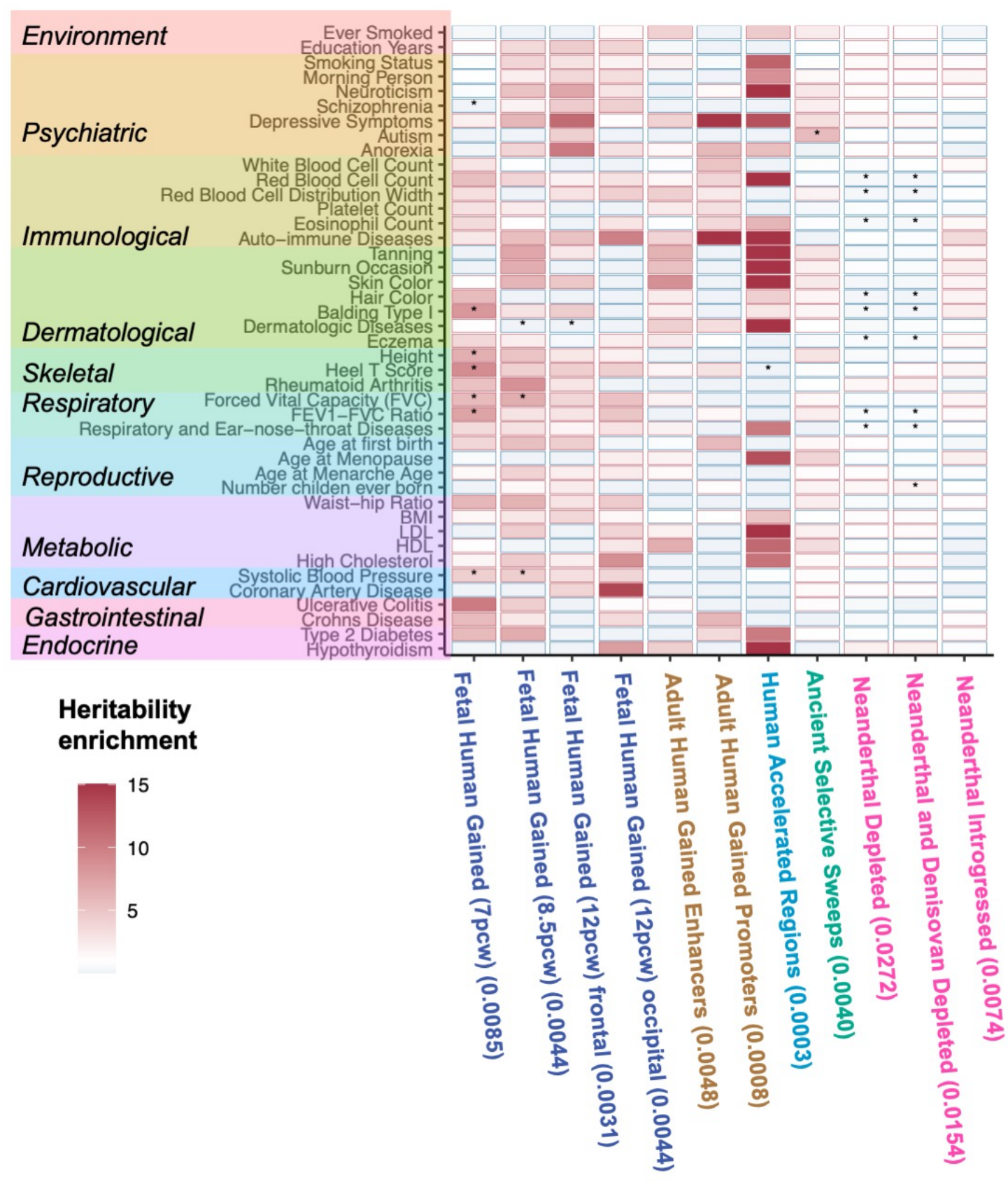

Figure 3. Heritability enrichment analysis for each trait. Each of 41 traits are shown in their trait domains from the GWAS atlas. Asterisks show significance at FDR $<0.05$ across genomic annotations and traits analyzed. Values in parenthesis indicate proportion of common SNPs that are in the annotation. This analysis was jointly performed with all genomic annotations in the baseline LDv2.2 170 model $(8,15,16,20)$. The fetal human-gained enhancers and promoters were further jointly analyzed with all fetal brain regulatory elements, and the adult human-gained enhancers and promoters with all adult cerebral cortex regulatory elements from the Epigenome Roadmap project (21).

Lastly, considering the period of inter-mating between humans and other hominids, we consider both variants putatively introgressed from Neanderthals, and genomic regions depleted in Neanderthal ancestry, or depleted in Neanderthal and Denisovan ancestry. Genomic regions that are depleted in Neanderthal and Denisovan ancestry are also depleted in heritability across 
bioRxiv preprint doi: https://doi.org/10.1101/2022.02.28.482389; this version posted March 1,2022. The copyright holder for this preprint (which was not certified by peer review) is the author/funder, who has granted bioRxiv a license to display the preprint in perpetuity. It is made available under aCC-BY-NC-ND 4.0 International license.

complex traits. We note that this signal of depletion primarily comes from such regions being significantly depleted in heritability for traits that are dermatological (hair color, balding type I, eczema), immunologic (red blood cell count, red blood cell distribution width, eosinophil count), and respiratory (FEV1-FVC ratio, respiratory and ear-nose-throat diseases), suggesting that Neanderthal and Denisovan ancestry persisted in genomic areas important especially for such traits also in line with previous work (Fig. 3, Fig. 5B, Figs. S13-15)(17, 24, 25). Interestingly, in regions depleted of Neanderthal ancestry, psychiatric traits as a domain are enriched in heritability $\left(h^{2}(C)=1.20, \mathrm{p}=9.99 \times 10^{-6}\right.$, Fig. 5B), and show a higher heritability enrichment compared to non-psychiatric traits (Wilcoxon $\mathrm{p}=3.21 \times 10^{-3}$ ) (Fig. 5B), implying that Neanderthal ancestry was particularly not tolerated in genomic regions that contribute disproportionately to psychiatric traits. Psychiatric traits show no significant heritability enrichment or depletion in the Neanderthal introgressed variants, and no other domain is significantly enriched after multiple-testing correction in the introgressed variants, while the metabolic trait domain is significantly depleted (Fig. 5B).

A

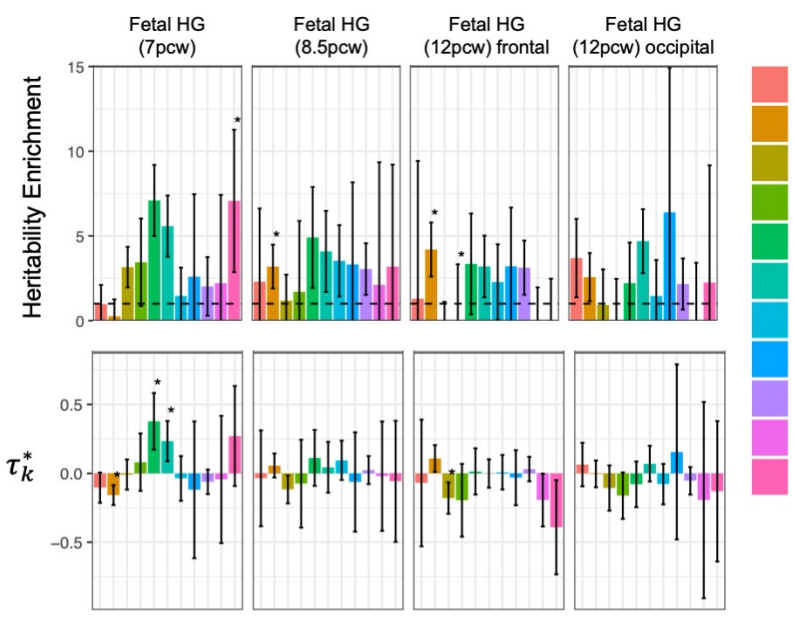

B

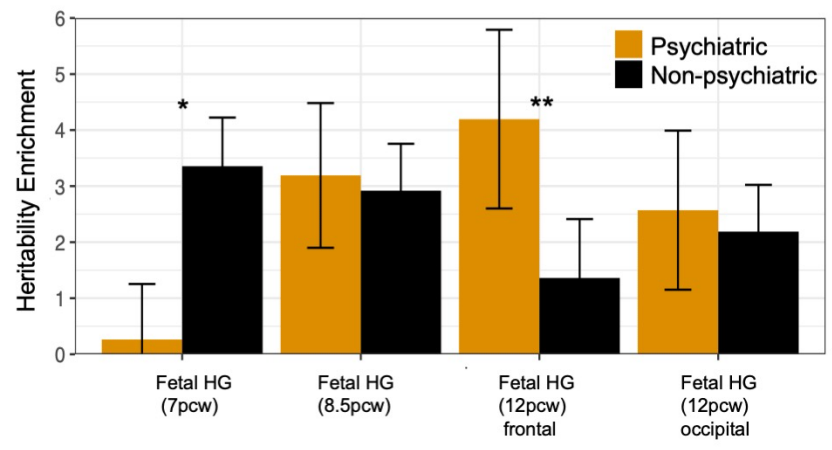

C

Environment Psychiatric Immunological Dermatological Skeletal Respiratory Reproductive Cardiovascular Metabolic Endocrine Gastrointestinal

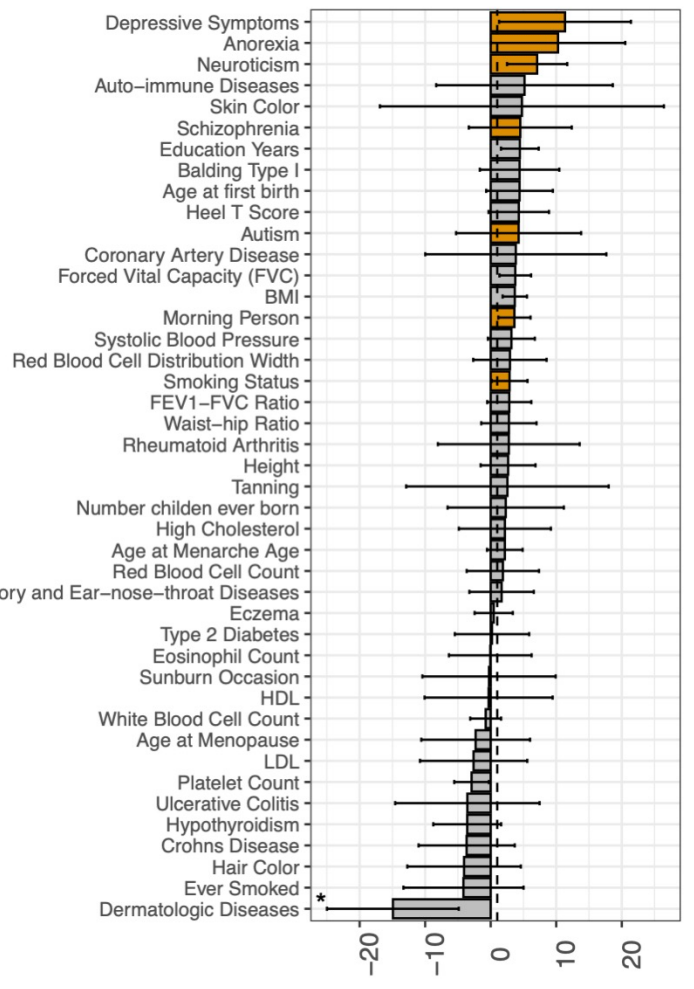

Heritability enrichment in Fetal HG frontal cortex enhancers and promoters (12pcw)

Figure 4. Heritability enrichment analyses across trait domains and traits in fetal human-gained enhancers and promoters in the cerebral cortex. (A) Heritability enrichment and $\tau_{k}^{*}$ analysis for all trait domains. Asterisks show significance at FDR $<0.05$ across all genomic annotations and trait domains analyzed in this study. Heritability enrichment estimates are from the joint analysis with all genomic annotations in the baselineLDv2.2 model $(8,15,16,20)$ and all fetal brain regulatory elements from the Epigenome Roadmap Project (21). $\tau_{k}^{*}$ analysis was jointly performed with all genomic annotations in the baseline model (15), and all fetal brain regulatory elements from the Epigenome Roadmap project (21). (B) Heritability enrichment analysis for the psychiatric trait domain relative to all 
bioRxiv preprint doi: https://doi.org/10.1101/2022.02.28.482389; this version posted March 1, 2022. The copyright holder for this preprint (which was not certified by peer review) is the author/funder, who has granted bioRxiv a license to display the preprint in perpetuity. It is made available under aCC-BY-NC-ND 4.0 International license.

non-psychiatric trait domains combined. Asterisks indicate significance $(* * p<0.005, * p<0.05$, Wilcoxon test, only comparisons significant at FDR $<0.05$ across all annotations are marked). (C) Heritability enrichment analysis in fetal human-gained frontal cortex enhancers and promoters at 12p.c.w. for each trait analyzed. Psychiatric traits are colored in yellow. Asterisks show significance at FDR $<0.05$ across all genomic annotations and traits analyzed in this study. A dashed line is drawn at $x=1$ (no heritability enrichment). Error bars show confidence intervals in all panels.

Our results demonstrate that epigenetic elements that gained novel function in the fetal brain since human divergence with rhesus macaque are likely involved in the development of several skeletal, dermatological, respiratory, and cardiovascular traits at 7 p.c.w. suggesting pleiotropic effects across the brain-body axis from our early evolution and life history. Prior
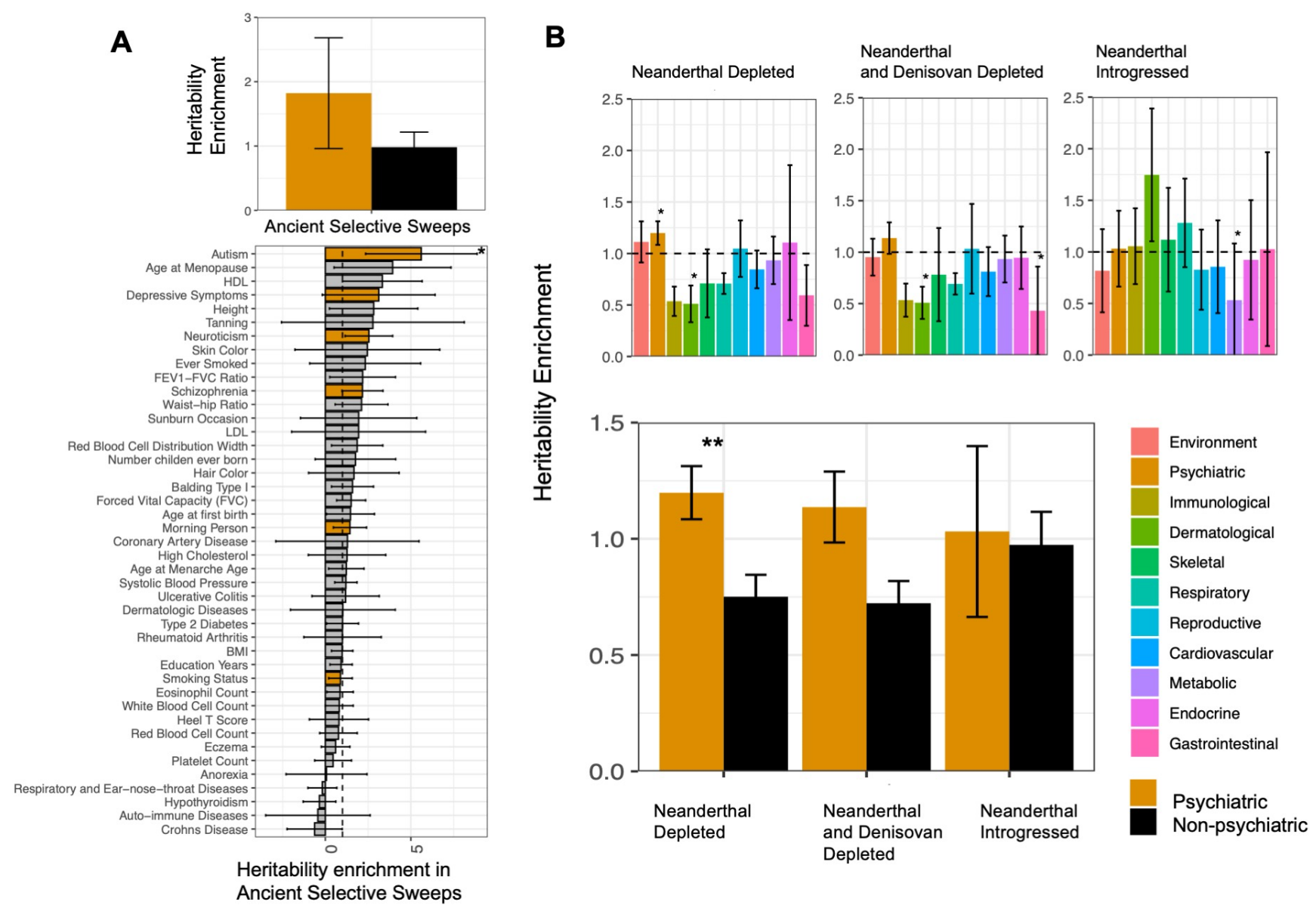

215 Figure 5. Heritability enrichment analyses across trait domains and traits in ancient selective sweeps and in genomic regions depleted in or introgressed with variants from other hominids. (A) Heritability enrichment analysis in ancient selective sweeps. (top) Heritability enrichment in the psychiatric trait domain relative to all non-psychiatric trait domains combined. (bottom) Heritability enrichment in each trait analyzed. Psychiatric traits are colored in yellow. Asterisks show significance at FDR $<0.05$ across all genomic annotations and traits analyzed in this study. A dashed line is drawn at $\mathrm{x}=1$ (no heritability enrichment). (B) Heritability enrichment in genomic segments depleted in or introgressed with variants from other hominids. (top) Heritability enrichment in different trait domains. Asterisks show significance at FDR $<0.05$ across all genomic annotations and trait domains analyzed in 
this study. (bottom) Heritability enrichment in the psychiatric trait domain relative to all non-psychiatric trait domains combined. Asterisks indicate significance $(* * \mathrm{p}<0.005, * \mathrm{p}<0.05$, Wilcoxon test, only comparisons significant at FDR $<0.05$ across all annotations are marked). Heritability enrichment estimates in all panels are from the joint analysis with all genomic annotations in the baselineLDv2.2 model $(8,15,16,20)$. Error bars show confidence intervals in all panels.

work also found that the same fetal human-gained epigenetic elements active at 7 p.c.w. explain a significant proportion of the heritability of the size (in surface area) of multiple brain regions (26). We observe that such fetal human-gained epigenetic marks are enriched in heritability for psychiatric trait architecture at a later developmental stage (8.5p.c.w, 12 p.c.w.), especially those epigenetic marks observed in the frontal cortex known to be involved in executive control, attention, memory, and motivation that are often disrupted in mental illness (23). As such, these human-gained epigenetic marks appear to be pleiotropically involved in psychiatric and nonpsychiatric traits, with such pleiotropic effects extending over developmental time.

Further, variants that lead to autism and schizophrenia today are mainly enriched in genetic regions that underwent selective sweeps since the time of our divergence with Neanderthals/Denisovans. Our results are in line with prior work that shows that autism associated variants are enriched for incomplete-selection, and schizophrenia associated variants are enriched in regions under selection detected using the Neanderthal selective sweep (NSS) score $(27,28)$. However, a limitation of our approach is that we study heritability enrichment only directly in the genomic regions of interest such as HARs which make up a small proportion of common SNPs limiting detection power. Previous work analyzing genes near HARs found an enrichment of schizophrenia-associated loci, also suggesting a role of this earlier period of human evolutionary history in the development of the genetic architecture of schizophrenia (29). HARs have also been implicated in creating genetic disposition for autism (30). Lastly, psychiatric traits as a group are more enriched in heritability in regions of the genome that became deserts of ancestry from other hominids. All these results point in the same direction. Psychiatric variation today is partly and significantly caused by regions of our genome, whether epigenetic or genetic, that played a role in human-specific evolution, in the divergence from ancestral lineages towards our present-day state. Specifically, a strong effect is noted in that genetic loci that affect autistic variation today were under selection in the lineage that led to present-day humans from our common ancestor with Neanderthals and Denisovans.

Our results imply that selection pressures on such traits may have changed over time, and/or that such traits have been pleiotropic with other traits beneficial to the human experience today or in our evolutionary past. Indeed, it has been shown that polygenic scores for schizophrenia predict creativity (31), and that creativity and psychopathology appear to have an

260 inverted-U shaped relationship (32), potentially due to overlapping mental processes involved in both creativity and psychosis proneness (33). For example, genetic correlation between several mental disorders and the personality dimension of openness has been demonstrated (34), and recent research in psychology suggests that "creative cognition draws on both the executive functioning that is tied to Intellect and the associative divergence that comes with Openness (35265 37). Being susceptible to schizophrenia spectrum disorders may enhance Openness, increasing the likelihood of ideas that are original. To develop ideas that are creative, however, one also needs protective intellectual factors (and autistic-like traits) to steer the chaotic storm (33)." It has also been hypothesized that autistic-like and schizotypal traits lead to different mating strategies, and may have been maintained in part by sexual selection through mate choice (38). 
Our analyses support the call for a shift in vocabulary presented in the introduction to one of "dimensions", "variability" and "prevention" from one of "disorder," "risk" and "cure." (1-6) They certainly call for research into understanding the nature and etiology of mental illness presentation today through the perspective of them being central to becoming and being a human being, and imply that dimensions of such traits are present across human variation today. They also invite inquiry into understanding differences in lifestyle or interactions with the environment that may have caused such genetic variants to be under positive selection in the past and to elevate the rate at which psychiatric conditions such as autism are manifested today, calling for research incorporating a deep evolutionary lens $(1-6)$.

\section{References and Notes}

1. M. A. Gernsbacher, On Not Being Human. APS Obs. 20, 5-32 (2007).

2. M. Yergeau, Clinically Significant Disturbance: On Theorists Who Theorize Theory of Mind. Disabil. Stud. Q. 33, 1-28 (2013).

3. R. Plomin, C. M. A. Haworth, O. S. P. Davis, Common disorders are quantitative traits. Nat. Rev. Genet. 10, 872-878 (2009).

4. R. Uher, The role of genetic variation in the causation of mental illness: an evolution-informed framework. Mol. Psychiatry. 14, 1072-82 (2009).

5. M. C. Keller, Evolutionary Perspectives on Genetic and Environmental Risk Factors for Psychiatric Disorders. Annu. Rev. Clin. Psychol. 14, 471-493 (2018).

6. M. L. Benton, A. Abraham, A. L. LaBella, P. Abbot, A. Rokas, J. A. Capra, The influence of evolutionary history on human health and disease. Nat. Rev. Genet. 22, 269-283 (2021).

7. S. Kawa, J. Giordano, A brief historicity of the Diagnostic and Statistical Manual of Mental Disorders: Issues and implications for the future of psychiatric canon and practice. Philos. Ethics, Humanit. Med. 7, 19 (2012).

8. M. L. A. Hujoel, S. Gazal, F. Hormozdiari, B. van de Geijn, A. L. Price, Disease Heritability Enrichment of Regulatory Elements Is Concentrated in Elements with Ancient Sequence Age and Conserved Function across Species. Am. J. Hum. Genet. 104, 611-624 (2019).

9. J. A. Capra, G. D. Erwin, G. Mckinsey, J. L. R. Rubenstein, K. S. Pollard, Many human accelerated regions are developmental enhancers. Philos. Trans. R. Soc. B Biol. Sci. (2013), doi:10.1098/rstb.2013.0025.

10. B. Vernot, S. Tucci, J. Kelso, J. G. Schraiber, A. B. Wolf, R. M. Gittelman, M. Dannemann, S. Grote, R. C. McCoy, H. Norton, L. B. Scheinfeldt, D. A. Merriwether, G. Koki, J. S. Friedlaender, J. Wakefield, S. Pääbo, J. M. Akey, Excavating Neandertal and Denisovan DNA from the genomes of Melanesian individuals. 352, 235-240 (2016).

11. S. K. Reilly, J. Yin, A. E. Ayoub, D. Emera, J. Leng, J. Cotney, R. Sarro, P. Rakic, J. P. Noonan, Evolutionary changes in promoter and enhancer activity during human corticogenesis. Science (80-. ). 347, 1155-1159 (2015).

12. M. W. Vermunt, S. C. Tan, B. Castelijns, G. Geeven, P. Reinink, E. De Bruijn, I. Kondova, S. Persengiev, R. Bontrop, E. Cuppen, W. De Laat, M. P. Creyghton, Epigenomic annotation of gene regulatory alterations during evolution of the primate brain. Nat. Neurosci. 19, 494-503 (2016).

13. S. R. Browning, B. L. Browning, Y. Zhou, S. Tucci, J. M. Akey, Analysis of Human Sequence Data Reveals Two Pulses of Archaic Denisovan Admixture. Cell. 173, 53-61.e9 (2018).

14. S. Peyregne, M. J. Boyle, M. Dannemann, K. Prufer, Detecting ancient positive selection in humans using extended lineage sorting. Genome Res. 27, 1563-1572 (2017).

15. H. K. Finucane, B. Bulik-Sullivan, A. Gusev, G. Trynka, Y. Reshef, P. R. Loh, V. Anttila, H. Xu, C. Zang, K. Farh, S. Ripke, F. R. Day, S. Purcell, E. Stahl, S. Lindstrom, J. R. B. Perry, Y. Okada, S. Raychaudhuri, 
M. J. Daly, N. Patterson, B. M. Neale, A. L. Price, Partitioning heritability by functional annotation using genome-wide association summary statistics. Nat. Genet. 47, 1228-1235 (2015).

16. S. Gazal, H. K. Finucane, N. A. Furlotte, P. R. Loh, P. F. Palamara, X. Liu, A. Schoech, B. Bulik-Sullivan, B. M. Neale, A. Gusev, A. L. Price, Linkage disequilibrium-dependent architecture of human complex traits shows action of negative selection. Nat. Genet. 49, 1421-1427 (2017).

17. E. McArthur, D. C. Rinker, J. A. Capra, Quantifying the contribution of Neanderthal introgression to the heritability of complex traits. Nat. Commun. 12, 1-14 (2021).

18. C. T. Miller, W. A. Freiwald, D. A. Leopold, J. F. Mitchell, A. C. Silva, X. Wang, Marmosets: A Neuroscientific Model of Human Social Behavior. Neuron. 90, 219-233 (2016).

19. K. Watanabe, S. Stringer, O. Frei, M. Umićević Mirkov, C. de Leeuw, T. J. C. Polderman, S. van der Sluis, O. A. Andreassen, B. M. Neale, D. Posthuma, A global overview of pleiotropy and genetic architecture in complex traits. Nat. Genet. 51, 1339-1348 (2019).

20. D. Marnetto, F. Mantica, I. Molineris, E. Grassi, I. Pesando, P. Provero, Evolutionary Rewiring of Human Regulatory Networks by Waves of Genome Expansion. Am. J. Hum. Genet. 102, 207-218 (2018).

21. Roadmap Epigenomics Consortium, A. Kundaje, W. Meuleman, J. Ernst, M. Bilenky, A. Yen, A. HeraviMoussavi, P. Kheradpour, Z. Zhang, J. Wang, M. J. Ziller, V. Amin, J. W. Whitaker, M. D. Schultz, L. D. Ward, A. Sarkar, G. Quon, R. S. Sandstrom, M. L. Eaton, Y. C. Wu, A. R. Pfenning, X. Wang, M. Claussnitzer, Y. Liu, C. Coarfa, R. A. Harris, N. Shoresh, C. B. Epstein, E. Gjoneska, D. Leung, W. Xie, R. D. Hawkins, R. Lister, C. Hong, P. Gascard, A. J. Mungall, R. Moore, E. Chuah, A. Tam, T. K. Canfield, R. S. Hansen, R. Kaul, P. J. Sabo, M. S. Bansal, A. Carles, J. R. Dixon, K. H. Farh, S. Feizi, R. Karlic, A. R. Kim, A. Kulkarni, D. Li, R. Lowdon, G. Elliott, T. R. Mercer, S. J. Neph, V. Onuchic, P. Polak, N. Rajagopal, P. Ray, R. C. Sallari, K. T. Siebenthall, N. A. Sinnott-Armstrong, M. Stevens, R. E. Thurman, J. Wu, B. Zhang, X. Zhou, A. E. Beaudet, L. A. Boyer, P. L. De Jager, P. J. Farnham, S. J. Fisher, D. Haussler, S. J. M. Jones, W. Li, M. A. Marra, M. T. McManus, S. Sunyaev, J. A. Thomson, T. D. Tlsty, L. H. Tsai, W. Wang, R. A. Waterland, M. Q. Zhang, L. H. Chadwick, B. E. Bernstein, J. F. Costello, J. R. Ecker, M. Hirst, A. Meissner, A. Milosavljevic, B. Ren, J. A. Stamatoyannopoulos, T. Wang, M. Kellis, Integrative analysis of 111 reference human epigenomes. Nature. 518, 317-329 (2015).

22. B. van de Geijn, H. Finucane, S. Gazal, F. Hormozdiari, T. Amariuta, X. Liu, A. Gusev, P. R. Loh, Y. Reshef, G. Kichaev, S. Raychauduri, A. L. Price, Annotations capturing cell type-specific TF binding explain a large fraction of disease heritability. Hum. Mol. Genet. 29, 1057-1067 (2021).

23. P. Pressman, H. J. Rosen, in Neurobiology of Brain Disorders, M. J. Zigmond, L. P. Rowland, J. T. Coyle, Eds. (Academic Press, 2015), pp. 542-557.

24. R. M. Gittelman, J. G. Schraiber, B. Vernot, C. Mikacenic, M. M. Wurfel, J. M. Akey, Archaic Hominin Admixture Facilitated Adaptation to Out-of-Africa Environments. Cell Curr. Biol. 26, 3375-3382 (2016).

C. N. Simonti, B. Vernot, L. Bastarache, E. Bottinger, D. S. Carrell, R. L. Chisholm, D. R. Crosslin, S. J. Hebbring, G. P. Jarvik, I. J. Kullo, R. Li, J. Pathak, J. D. Prato, W. S. Bush, J. M. Akey, J. C. Denny, J. A. Capra, The phenotypic legacy of admixture between modern humans and Neanderthals. Science (80-. ). 351, 737-741 (2016).

26. A. K. Tilot, E. A. Khramtsova, D. Liang, K. L. Grasby, N. Jahanshad, J. Painter, L. Colodro-Conde, J. Bralten, D. P. Hibar, P. A. Lind, S. Liu, S. M. Brotman, P. M. Thompson, S. E. Medland, F. Macciardi, B. E. Stranger, L. K. Davis, S. E. Fisher, J. L. Stein, The Evolutionary History of Common Genetic Variants Influencing Human Cortical Surface Area. Cereb. Cortex. 31, 1873-1887 (2021).

27. R. Polimanti, J. Gelernter, Widespread signatures of positive selection in common risk alleles associated to autism spectrum disorder. PLoS Genet. 13, 1-14 (2017).

28. S. Srinivasan, F. Bettella, M. Mattingsdal, Y. Wang, A. Witoelar, A. J. Schork, W. K. Thompson, V. Zuber, B. S. Winsvold, J. A. Zwart, D. A. Collier, R. S. Desikan, I. Melle, T. Werge, A. M. Dale, S. Djurovic, O. A. Andreassen, Genetic Markers of Human Evolution Are Enriched in Schizophrenia. Biol. Psychiatry. 80, 284-292 (2016).

29. K. Xu, E. E. Schadt, K. S. Pollard, P. Roussos, J. T. Dudley, Genomic and network patterns of schizophrenia genetic variation in human evolutionary accelerated regions. Mol. Biol. Evol. 32, 1148-1160 (2015). 
30. R. N. Doan, B. Il Bae, B. Cubelos, C. Chang, A. A. Hossain, S. Al-Saad, N. M. Mukaddes, O. Oner, M. AlSaffar, S. Balkhy, G. G. Gascon, M. Nieto, C. A. Walsh, Mutations in Human Accelerated Regions Disrupt Cognition and Social Behavior. Cell. 167, 341-354.e12 (2016).

31. R. A. Power, S. Steinberg, G. Bjornsdottir, C. A. Rietveld, A. Abdellaoui, M. M. Nivard, M. Johannesson, T. E. Galesloot, J. J. Hottenga, G. Willemsen, D. Cesarini, D. J. Benjamin, P. K. E. Magnusson, F. Ullén, H. Tiemeier, A. Hofman, F. J. A. Van Rooij, G. B. Walters, E. Sigurdsson, T. E. Thorgeirsson, A. Ingason, A. Helgason, A. Kong, L. A. Kiemeney, P. Koellinger, D. I. Boomsma, D. Gudbjartsson, H. Stefansson, K. Stefansson, Polygenic risk scores for schizophrenia and bipolar disorder predict creativity. Nat. Neurosci. 18, 953-955 (2015).

32. S. Acar, X. Chen, N. Cayirdag, Schizophrenia and creativity: A meta-analytic review. Schizophr. Res. 195, 23-31 (2018).

33. S. B. Kaufman, E. S. Paul, Creativity and schizophrenia spectrum disorders across the arts and sciences. Front. Psychol. 5, 3-6 (2014).

34. M.-T. Lo, D. A. Hinds, J. Y. Tung, C. Franz, C.-C. Fan, Y. Wang, O. B. Smeland, A. Schork, D. Holland, K. Kauppi, N. Sanyal, V. Escott-Price, D. J. Smith, M. O’Donovan, H. Stefansson, G. Bjornsdottir, T. E. Thorgeirsson, K. Stefansson, L. K. McEvoy, A. M. Dale, O. A. Andreassen, C.-H. Chen, Genome-wide analyses for personality traits identify six genomic loci and show correlations with psychiatric disorders. Nat. Genet. 49, 1-8 (2016).

35. R. E. Beaty, P. J. Silvia, E. C. Nusbaum, E. Jauk, M. Benedek, The roles of associative and executive processes in creative cognition. Mem. Cogn. 42, 1186-1197 (2014).

36. R. E. Jung, Evolution, creativity, intelligence, and madness: "Here Be Dragons." Front. Psychol. 5, 1-3 (2014).

37. E. C. Nusbaum, P. J. Silvia, Are intelligence and creativity really so different?. Fluid intelligence, executive processes, and strategy use in divergent thinking. Intelligence. 39, 36-45 (2011).

38. M. Del Giudice, R. Angeleri, A. Brizio, M. R. Elena, The evolution of autistic-like and schizotypal traits: A sexual selection hypothesis. Front. Psychol. 1, 1-18 (2010).

39. F. Hormozdiari, B. van de Geijn, J. Nasser, O. Weissbrod, S. Gazal, C. J. T. Ju, L. O. Connor, M. L. A. Hujoel, J. Engreitz, F. Hormozdiari, A. L. Price, Functional disease architectures reveal unique biological role of transposable elements. Nat. Commun. 10 (2019), doi:10.1038/s41467-019-11957-5.

40. Y. Benjamini, Y. Hochberg, Controlling the False Discovery Rate: A Practical and Powerful Approach to Multiple Testing. J. R. Stat. Soc. Ser. B. 57, 289-300 (1995).

41. A. Auton, G. R. Abecasis, D. M. Altshuler, R. M. Durbin, D. R. Bentley, A. Chakravarti, A. G. Clark, P. Donnelly, E. E. Eichler, P. Flicek, S. B. Gabriel, R. A. Gibbs, E. D. Green, M. E. Hurles, B. M. Knoppers, J. O. Korbel, E. S. Lander, C. Lee, H. Lehrach, E. R. Mardis, G. T. Marth, G. A. McVean, D. A. Nickerson, J. P. Schmidt, S. T. Sherry, J. Wang, R. K. Wilson, E. Boerwinkle, H. Doddapaneni, Y. Han, V. Korchina, C. Kovar, S. Lee, D. Muzny, J. G. Reid, Y. Zhu, Y. Chang, Q. Feng, X. Fang, X. Guo, M. Jian, H. Jiang, X. Jin, T. Lan, G. Li, J. Li, Y. Li, S. Liu, X. Liu, Y. Lu, X. Ma, M. Tang, B. Wang, G. Wang, H. Wu, R. Wu, X. Xu, Y. Yin, D. Zhang, W. Zhang, J. Zhao, M. Zhao, X. Zheng, N. Gupta, N. Gharani, L. H. Toji, N. P. Gerry, A. M. Resch, J. Barker, L. Clarke, L. Gil, S. E. Hunt, G. Kelman, E. Kulesha, R. Leinonen, W. M. McLaren, R. Radhakrishnan, A. Roa, D. Smirnov, R. E. Smith, I. Streeter, A. Thormann, I. Toneva, B. Vaughan, X. Zheng-Bradley, R. Grocock, S. Humphray, T. James, Z. Kingsbury, R. Sudbrak, M. W. Albrecht, V. S. Amstislavskiy, T. A. Borodina, M. Lienhard, F. Mertes, M. Sultan, B. Timmermann, M.-L. Yaspo, L. Fulton, R. Fulton, V. Ananiev, Z. Belaia, D. Beloslyudtsev, N. Bouk, C. Chen, D. Church, R. Cohen, C. Cook, J. Garner, T. Hefferon, M. Kimelman, C. Liu, J. Lopez, P. Meric, C. O’Sullivan, Y. Ostapchuk, L. Phan, S. Ponomarov, V. Schneider, E. Shekhtman, K. Sirotkin, D. Slotta, H. Zhang, S. Balasubramaniam, J. Burton, P. Danecek, T. M. Keane, A. Kolb-Kokocinski, S. McCarthy, J. Stalker, M. Quail, C. J. Davies, J. Gollub, T. Webster, B. Wong, Y. Zhan, C. L. Campbell, Y. Kong, A. Marcketta, F. Yu, L. Antunes, M. Bainbridge, A. Sabo, Z. Huang, L. J. M. Coin, L. Fang, Q. Li, Z. Li, H. Lin, B. Liu, R. Luo, H. Shao, Y. Xie, C. Ye, C. Yu, F. Zhang, H. Zheng, H. Zhu, C. Alkan, E. Dal, F. Kahveci, E. P. M. A. DePristo, R. E. Handsaker, E. Banks, G. Bhatia, G. del Angel, G. Genovese, H. Li, S. Kashin, S. A. 
bioRxiv preprint doi: https://doi.org/10.1101/2022.02.28.482389; this version posted March 1,2022. The copyright holder for this preprint (which was not certified by peer review) is the author/funder, who has granted bioRxiv a license to display the preprint in perpetuity. It is made available under aCC-BY-NC-ND 4.0 International license.

McCarroll, J. C. Nemesh, R. E. Poplin, S. C. Yoon, J. Lihm, V. Makarov, S. Gottipati, A. Keinan, J. L. Rodriguez-Flores, T. Rausch, M. H. Fritz, A. M. Stütz, K. Beal, A. Datta, J. Herrero, G. R. S. Ritchie, D. Zerbino, P. C. Sabeti, I. Shlyakhter, S. F. Schaffner, J. Vitti, D. N. Cooper, E. V. Ball, P. D. Stenson, B. Barnes, M. Bauer, R. Keira Cheetham, A. Cox, M. Eberle, S. Kahn, L. Murray, J. Peden, R. Shaw, E. E. Kenny, M. A. Batzer, M. K. Konkel, J. A. Walker, D. G. MacArthur, M. Lek, R. Herwig, L. Ding, D. C. Koboldt, D. Larson, K. Ye, S. Gravel, A. Swaroop, E. Chew, T. Lappalainen, Y. Erlich, M. Gymrek, T. Frederick Willems, J. T. Simpson, M. D. Shriver, J. A. Rosenfeld, C. D. Bustamante, S. B. Montgomery, F. M. De La Vega, J. K. Byrnes, A. W. Carroll, M. K. DeGorter, P. Lacroute, B. K. Maples, A. R. Martin, A. Moreno-Estrada, S. S. Shringarpure, F. Zakharia, E. Halperin, Y. Baran, E. Cerveira, J. Hwang, A. Malhotra, D. Plewczynski, K. Radew, M. Romanovitch, C. Zhang, F. C. L. Hyland, D. W. Craig, A. Christoforides, N. Homer, T. Izatt, A. A. Kurdoglu, S. A. Sinari, K. Squire, C. Xiao, J. Sebat, D. Antaki, M. Gujral, A. Noor, K. Ye, E. G. Burchard, R. D. Hernandez, C. R. Gignoux, D. Haussler, S. J. Katzman, W. James Kent, B. Howie, A. Ruiz-Linares, E. T. Dermitzakis, S. E. Devine, H. Min Kang, J. M. Kidd, T. Blackwell, S. Caron, W. Chen, S. Emery, L. Fritsche, C. Fuchsberger, G. Jun, B. Li, R. Lyons, C. Scheller, C. Sidore, S. Song, E. Sliwerska, D. Taliun, A. Tan, R. Welch, M. Kate Wing, X. Zhan, P. Awadalla, A. Hodgkinson, Y. Li, X. Shi, A. Quitadamo, G. Lunter, J. L. Marchini, S. Myers, C. Churchhouse, O. Delaneau, A. Gupta-Hinch, W. Kretzschmar, Z. Iqbal, I. Mathieson, A. Menelaou, A. Rimmer, D. K. Xifara, T. K. Oleksyk, Y. Fu, X. Liu, M. Xiong, L. Jorde, D. Witherspoon, J. Xing, B. L. Browning, S. R. Browning, F. Hormozdiari, P. H. Sudmant, E. Khurana, C. Tyler-Smith, C. A. Albers, Q. Ayub, Y. Chen, V. Colonna, L. Jostins, K. Walter, Y. Xue, M. B. Gerstein, A. Abyzov, S. Balasubramanian, J. Chen, D. Clarke, Y. Fu, A. O. Harmanci, M. Jin, D. Lee, J. Liu, X. Jasmine Mu, J. Zhang, Y. Zhang, C. Hartl, K. Shakir, J. Degenhardt, S. Meiers, B. Raeder, F. Paolo Casale, O. Stegle, E.-W. Lameijer, I. Hall, V. Bafna, J. Michaelson, E. J. Gardner, R. E. Mills, G. Dayama, K. Chen, X. Fan, Z. Chong, T. Chen, M. J. Chaisson, J. Huddleston, M. Malig, B. J. Nelson, N. F. Parrish, B. Blackburne, S. J. Lindsay, Z. Ning, Y. Zhang, H. Lam, C. Sisu, D. Challis, U. S. Evani, J. Lu, U. Nagaswamy, J. Yu, W. Li, L. Habegger, H. Yu, F. Cunningham, I. Dunham, K. Lage, J. Berg Jespersen, H. Horn, D. Kim, R. Desalle, A. Narechania, M. A. Wilson Sayres, F. L. Mendez, G. David Poznik, P. A. Underhill, L. Coin, D. Mittelman, R. Banerjee, M. Cerezo, T. W. Fitzgerald, S. Louzada, A. Massaia, G. R. Ritchie, F. Yang, D. Kalra, W. Hale, X. Dan, K. C. Barnes, C. Beiswanger, H. Cai, H. Cao, B. Henn, D. Jones, J. S. Kaye, A. Kent, A. Kerasidou, R. Mathias, P. N. Ossorio, M. Parker, C. N. Rotimi, C. D. Royal, K. Sandoval, Y. Su, Z. Tian, S. Tishkoff, M. Via, Y. Wang, H. Yang, L. Yang, J. Zhu, W. Bodmer, G. Bedoya, Z. Cai, Y. Gao, J. Chu, L. Peltonen, A. Garcia-Montero, A. Orfao, J. Dutil, J. C. Martinez-Cruzado, R. A. Mathias, A. Hennis, H. Watson, C. McKenzie, F. Qadri, R. LaRocque, X. Deng, D. Asogun, O. Folarin, C. Happi, O. Omoniwa, M. Stremlau, R. Tariyal, M. Jallow, F. Sisay Joof, T. Corrah, K. Rockett, D. Kwiatkowski, J. Kooner, T. Tịnh Hiê`n, S. J. Dunstan, N. Thuy Hang, R. Fonnie, R. Garry, L. Kanneh, L. Moses, J. Schieffelin, D. S. Grant, C. Gallo, G. Poletti, D. Saleheen, A. Rasheed, L. D. Brooks, A. L. Felsenfeld, J. E. McEwen, Y. Vaydylevich, A. Duncanson, M. Dunn, J. A. Schloss, A global reference for human genetic variation. Nature. 526, 68-74 (2015).

42. D. M. Altshuler, R. A. Gibbs, L. Peltonen, S. F. Schaffner, F. Yu, E. Dermitzakis, P. E. Bonnen, P. I. W. De Bakker, P. Deloukas, S. B. Gabriel, R. Gwilliam, S. Hunt, M. Inouye, X. Jia, Aarno Palotie, M. Parkin, P. Whittaker, K. Chang, A. Hawes, L. R. Lewis, Y. Ren, D. Wheeler, D. M. Muzny, C. Barnes, K. Darvishi, M. Hurles, J. M. Korn, K. Kristiansson, C. Lee, S. A. McCarroll, J. Nemesh, A. Keinan, S. B. Montgomery, Samuela Pollack, A. L. Price, N. Soranzo, C. Gonzaga-Jauregui, V. Anttila, W. Brodeur, M. J. Daly, S. Leslie, G. McVean, L. Moutsianas, H. Nguyen, Q. Zhang, M. J. R. Ghori, R. McGinnis, W. McLaren, S. Pollack, F. Takeuchi, S. R. Grossman, I. Shlyakhter, E. B. Hostetter, P. C. Sabeti, C. A. Adebamowo, M. W. Foster, D. R. Gordon, J. Licinio, M. C. Manca, P. A. Marshall, I. Matsuda, D. Ngare, V. O. Wang, D. Reddy, C. N. Rotimi, C. D. Royal, R. R. Sharp, C. Zeng, D. B. Brooks, J. E. McEwen, Integrating common and rare genetic variation in diverse human populations. Nature. 467, 52-58 (2010).

Acknowledgments: We would like to thank John Novembre and Steven Gazal for helpful discussions and valuable comments on earlier drafts of this manuscript, John Capra and Evonne McArthur for sharing information about Neanderthal introgressed variants, Amanda Tilot for help with accessing human-gained epigenetic annotations, Peter Carbonetto for help with the computing cluster at U Chicago, and Daniel Quesada Lombó for assistance with figure design.

\section{Funding:}


Chicago Fellows Award from the Biological Sciences Division at University of Chicago (MS)

Competing interests: Authors declare that they have no competing interests.

Data and materials availability: All datasets and code used in the study will be made available in a github repository on publication: https://github.com/msohail88/SLDSC evolution.

\section{Supplementary Materials}

Materials and Methods

Supplementary Text

Figs. S1 to S18

Table S1 to S2

References (39-42) 